\title{
Sociologia de um grupo familiar administrador de uma escola de elite em São Luis do Maranhão
}

\author{
Juarez Lopes Carvalho Filho \\ Universidade Federal do Maranhão, Brasil \\ (iD) https://orcid.org/0000-0002-3508-4959 \\ juarez.lopes@gmail.com \\ Leandro Augusto dos Remédios Costa \\ Universidade Federal do Maranhão, Brasil \\ (iD) https://orcid.org/0000-0002-8608-7252 \\ leandroaugustocosta7@gmail.com
}

\section{Introdução ${ }^{1}$}

O presente trabalho propõe uma análise da trajetória social e escolar de um grupo familiar fundador de uma escola de elite de São Luís e

\footnotetext{
${ }^{1} \mathrm{O}$ presente artigo foi apresentado em outra versão sob o título "Origem social e trajetórias de escolarização no grupo familiar de uma”escola de elite” de São Luís do Maranhão”, na XIX Jornada de Políticas Públicas, realizada em agosto de 2019, na Universidade Federal do Maranhão, São Luís-MA. A versão apresentada aqui contou com alterações substanciais em todas as seções, no que diz respeito ao estilo e ao conteúdo, operadas em comum acordo com os autores.
} 
um instituto de idiomas. Esse artigo é um dos resultados de uma pesquisa cuja ênfase foi dada sobre as "escolas de elite" " de São Luís buscando objetivar os processos de escolarização e socialização das “elites”, e como esses processos podem desvelar o jogo das diferenciações econômica, social e escolar como estratégias de reprodução social da classe dirigente. As “escolas de elite” nessa pesquisa são definidas como escolas da rede privada de ensino, caracterizadas pelo alto padrão de ensino, cuja clientela são as famílias que podem arcar com mensalidades com alto poder aquisitivo, muito acima das demais. Esses estabelecimentos de ensino ficam localizados nos bairros considerados os mais ricos da cidade de São Luís, ${ }^{3}$ que monopolizam as primeiras posições dos rankings produzidos a partir do ENEM (Exame Nacional do Ensino Médio) e, consequentemente, têm altas taxas de aprovação dos seus alunos nos cursos mais concorridos e mais prestigiosos das universidades públicas do Maranhão: Medicina, Direito e

\footnotetext{
${ }^{2}$ Os termos "escolas de elite” e "elite” são utilizados aqui de modo relacional, evitando, assim, visões substancializadas. "Escolas de elite” não estão sendo pensadas como escolas nas quais só estudam “a elite” (não existe do nosso ponto de vista a elite em sentido único ou verdadeiro), mas sim, como escolas que em relação às demais, encontram-se no topo das hierarquias escolares e sociais, amplamente reconhecidas (como por exemplo, todas estão nos bairros mais ricos da cidade, e figuram entre as dez primeiras nos rankings do ENEM). Da mesma forma o termo “elite” é relacional e depende do espaço social e simbólico que se analisa, podendo se referir a uma elite educacional, a uma elite econômica ou a uma elite política etc.

${ }^{3}$ São Luís é uma cidade de 1 milhão e 100 mil habitantes fundada em 1612. A partir de 1990, o espaço urbano se apresenta com características muito específicas com um processo de expansão da sua malha urbana, com investimentos mais volumosos no setor da construção civil direcionados a habitações verticais nos bairros da orla marítima e entorno, a saber: Calhau, Ponta d'Areia, Ponta do Farol, Altos do Calhau, Renascença, Olho d'Água, para citar apenas esses. Nos bairros Renascença e Calhau, que são vizinhos, se concentra a maioria das escolas e faculdades da rede privada com alto valor de suas mensalidades, consideradas aqui como "escolas de elite econômica e política”. É aí que se concentram, também, melhor infraestrutura urbana, equipamentos com melhores serviços tais como bancos, shoppings, escritórios, consultórios etc.
} 
Engenharia.

Este artigo se insere num conjunto de trabalhos em escala nacional e internacional que colocam ênfase nas estratégias de escolarização e reprodução social das famílias através de suas relações com a Escola, seja nas camadas chamadas de “elites”, seja nas trajetórias escolares das classes médias e populares. No que tange aos estudos sobre escolas “de elite” ou escolarização das “elites”, podemos citar, no contexto brasileiro, os trabalhos "Elites acadêmicas e escolarização dos filhos”, por Zaia Brandão e Isabel Lellis (2003), "Favorecimento econômico e excelência escolar: um mito em questão”, de Maria Alice Nogueira (2004); “A circularidade virtuosa: investigação sobre duas escolas do Rio de Janeiro”, de Zaia Brandão et al (2005); “Contextos institucionais e escolarização: uma hipótese de classificação das escolas privadas de educação básica”, por Cynhia Paes de Carvalho (2006); e “Educação diferenciada e trajetórias profissionais femininas”, de Graziela Perosa (2008).

Dois desses trabalhos acentuam aspectos importantes sobre as escolas analisadas que indicam caminhos consoantes com a nossa pesquisa. Brandão, Manderlet e Paula (2005) afirmam, sobre duas escolas privadas e prestigiosas do Rio de Janeiro, que tais escolas formam uma "circularidade virtuosa" quando a estrutura física de qualidade, um projeto político pedagógico e profissionais experientes e qualificados garantem que um perfil "ideal" de pais matricule seus filhos nessas escolas e garanta a efetivação da excelência acadêmica dessas instituições. Perosa (2008), em seu trabalho sobre educação diferenciada e trajetórias femininas em São Paulo, constata que existe um alto grau de ajustamento entre escolas privadas e expectativas das famílias de grupos intermediários e dominantes, o que é decisivo para reprodução de privilégios. Estes dois trabalhos citados aqui, destacam 
as características das escolas que são relativamente próximas àquelas que encontramos no Colégio Inovação, bem como relacionam essas características com as famílias ligadas a escolas, indicando que a relação entre famílias e escolas é um caminho que esta pesquisa pode seguir. Nesse aspecto, os trabalho de Brandão e Lellis (2003) e Nogueira (2004), que enfatizam as famílias em suas análises nos respectivos contextos do Rio de Janeiro e Minas Gerais, serão úteis para uma reflexão comparativa ulteriormente.

Em termos metodológicos, nossa pesquisa se caracterizou como um estudo de caso sobre esse grupo social a fim de compreender suas estratégias de reconversão do capital social e simbólico de uma família. Estudos dessa natureza, cujo objetivo é trazer a lume informações qualitativas através de um estudo específico de um caso determinado, podem contribuir para uma melhor compreensão e explicação dos processos de escolarização e socialização das “elites” desvelando suas estratégias de reprodução social.

Os dados empíricos foram construídos através de entrevista e leitura de documentos escritos de autoria do próprio agente entrevistado, um dos proprietários das instituições escolares analisadas. Cabe ressaltar que, apesar de um dos agentes ligado a escola ter um lugar mais destacado no trabalho empírico (por conta da entrevista realizada e de termos o seu livro como fonte), este agente serviu de informante sobre a trajetória e as características sociais de sua esposa (também proprietária da escola) e de seus filhos, caracterizando, assim, o grupo familiar que administra a escola e suas origens sociais. Essa coleção de materiais empíricos pode ser classificada em Sociologia como materiais biográficos que encontra sua tradição sociológica na Escola de Chicago desde o final do século XIX e início do século XX, e amplamente desenvolvido na Sociologia contemporânea desde a década de 
1980 (DUBAR; NICOURD, 2017). Trata-se, nesse sentido, de “articular percursos socioindividuais típicos às dinâmicas de instituições, de ações coletivas ou de interações, situadas em contextos sociohistóricos definidos. Essa perspectiva se esforça para dar um sentido sociológico às experiências biográficas coligidas de diversas maneiras” (DUBAR; NICOURD, 2017, p. 5). ${ }^{4}$

Sobressaem nos relatos que iremos apresentar e analisar, estratégias de reconversão social e simbólica através de investimentos escolares e financeiros cujos discursos se pautam nas mesmas perspectivas do discurso do empreendedorismo e da inovação que tem invadido os sistemas escolares e educacionais no mundo inteiro e, especificamente, no Brasil nos últimos anos, no sistema escolar seja em nível fundamental e médio e no sistema universitário. Postulamos aqui, que esse discurso se alinha ao discurso sustentado pela "escola neoliberal”, que, segundo Christian Laval,

é a designação de certo modelo escolar que considera a educação um bem essencialmente privado, cujo valor é acima de tudo econômico. Não é a sociedade que garante o direito à cultura a seus membros; são os indivíduos que devem capitalizar recursos privados cujo rendimento futuro será garantido pela sociedade (LAVAL, 2019, p. 17).

Segundo Laval (2019), a expansão do modelo da escola neoliberal no espaço escolar e universitário concebe essas instituições como um lugar de um certo tipo de subjetividade, de criação de um "capital humano”, pensado como tal e que é reputado a alimentar um sistema político fundado numa concorrência generalizada e permanente. De autoria de Gary Becker, americano, Nobel de Economia em 1992, a teoria do capital humano enfatiza o aporte da formação escolar no crescimento econômico. Ele propõe uma análise econômica "racio-

\footnotetext{
${ }^{4}$ Tradução livre, exceto quando indicado.
} 
nal” das escolhas individuais em matéria de educação. Como relembra Laval (2019),

Hoje o centro de gravidade da doutrina dominante na educação se encontra nas teorias do capital humano. Estas últimas, por mais que sejam enviesadas ideologicamente, traduzem uma tendência muito real do capitalismo contemporâneo de mobilizar saberes em número cada vez maior, sob o duplo aspecto de fator de produção e mercadoria (LAVAL, 2019, p. 51). ${ }^{5}$

Dito de outra maneira, a escola neoliberal é uma escola que está fundada na eficiência, na performance, e na rentabilidade, que deve começar na prima infância. A observação atenta aos métodos pedagógicos difusos nas escolas privadas (e, também, nas públicas) em São Luís e alhures, nos indica que praticamente todos eles se alinham ao discurso da autogestão. É preciso que o aluno, muito cedo seja o empreendedor e gestor de si mesmo. Colocando em paralelo o modo de funcionamento da empresa e da escola, Jean-Pierre Le Goff (1999) mostra em que aspecto a escola programa as crianças à empresa, valorizando muito cedo a autonomia do aluno, a autodisciplina e preparando-o à autoavaliação. As duas instituições têm em comum o discurso de legitimação que na prática denega a responsabilidade e o poder daqueles que os exercem, pretendendo contribuir com a emancipação daqueles que lhes estão submetidos.

\footnotetext{
${ }^{5}$ Convém lembrar que Pierre Bourdieu forjou a noção de capital cultural para confrontar com essa noção de capital humano de G. Becker : “A noção de capital cultural impôs-se, primeiramente, como uma hipóteses indispensável para dar conta da desigualdade de desempenho escolar de crianças provenientes das diferentes classes sociais, relacionando o”sucesso escolar“, ou seja, os benefícios específicos que as crianças das diferentes classes e frações de classe podem obter no mercado escolar, à distribuição do capital cultural entre as classes e frações de classe. Este ponto de partida implica uma ruptura com os pressupostos inerentes, tanto à visão comum que considera o sucesso ou fracasso escolar como efeito das”aptidões” naturais quanto às teorias do capital humano” (BOURDIEU, 2017, p. 81).
} 
Busca-se aqui apreender as propriedades sociais e estratégias de reprodução de um grupo doméstico e social que detém em São Luís do Maranhão a posse e a administração de dois empreendimentos educacionais, a saber: o Colégio Inovação e um instituto de idiomas, nomeado aqui de Tecnology. ${ }^{6}$ Temos também, o propósito de identificar as estratégias de distinção social dessa escola no espaço educacional ludovicense. ${ }^{7}$ Apresentaremos, desse modo, as propriedades sociais do grupo, em seguida as estratégias de mise en place dessas duas instituições.

\section{Algumas propriedades sociais de um grupo familiar}

A história de uma instituição escolar da rede privada de ensino está diretamente ligada à história social do seu fundador. O presente trabalho enseja reconstituir a história social e a trajetória de escolarização de um grupo familiar que detém uma escolar privada “de elite”, em São Luís, O Colégio Inovação, caracterizado por altas mensalidade e incitação à competição no acesso aos cursos superiores de alto prestígio.

Os dados e as informações apresentadas aqui, que fundamentam nossa análise, foram coligidas através de entrevista direta concedia por Agostinho Martins (trata-se de nome fictício) um dos proprietários das escolas em questão e um livro escrito por ele, intitulado “Aonde você for eu vou: 40 anos do Technology em São Luís”. Nesse livro ele reconstitui a história de um empreendimento da família cujas instituições são hoje de referência na cidade de São Luís.

\footnotetext{
${ }^{6}$ Ambas as instituições aqui são nomeadas com nomes fictícios.

${ }^{7}$ Diz-se ludovicence aquele que nasceu ou mora em São Luís do Maranhão.
} 
Para atingir nosso objetivo foi importante e necessário apreender algumas propriedades sociais objetivas que revelam a origem social e a trajetória percorrida por nossos agentes em termos de escolarização e tentativas de acesso a categorias socioprofissionais.

Agostinho Martins nasceu em Buriti Maranhão mais conhecido como Buriti de Inácia Vaz (leste do Estado, a $327 \mathrm{Km}$ da capital). É filho de pais lavradores nascidos em Barro Branco, interior de Buriti, assim como seus irmãos mais velhos. Seu pai foi também coletor fiscal estadual o que, segundo ele, os fazia mudar de cidade a cada dois ou três anos.

O primeiro capítulo do livro citado acima revela um pouco da trajetória do pai de Agostinho. Segundo informações colhidas, seu pai, trabalhador rural, após deixar a roça e vender o que tinha, abriu um pequeno comércio. Algum tempo depois, conseguiu ampliar seu negócio comercial e foi indicado para ser coletor estadual (da Secretaria da Fazenda, antiga Mesa de Renda). Duas observações cabem aqui: a primeira é que não ficamos informados do volume do capital fundiário que a família possuía naquele momento. Em artigo de Pierre Bourdieu (1986, p. 69), l'illusion biographique, bastante discutido e comentado entre os que trabalham com trajetórias e biografias, o autor critica a ilusão, segundo a qual a vida seria uma "história" no sentido de um "conjunto de sequências ordenadas de acordo com relações inteligíveis” engendrando, desse modo, uma "criação artificial de sentido" (BOURDIEU, 1986, p. 69; DUBAR; NICOURD, 2017, p. 33), como se existisse um discurso totalmente construído (DUBAR; NICOURD, 2017, p. 33). No que diz respeito à denegação, os depoimentos que os sociólogos reúnem nas suas entrevistas, contém sempre zonas de opacidade, de traços de construção e de reconstrução através de percursos sinuosos (SCHWARTZ, 1990 apud DUBAR, NICOURD, 2017, 
p. 33). A outra observação é a respeito do cargo público obtido à época. Apenas a posse de comércio não é suficiente para obtenção de tal cargo público, quando sabemos que, nesses casos e, naquela época, as indicações eram feitas através de rede de relações sociais ou clientelistas, notadamente com meios políticos. Por conta dessa função pública, segundo nosso interlocutor, a família foi algumas vezes transferida para várias cidades, como Chapadinha (também no leste do estado do Maranhão a $247 \mathrm{Km}$ da capital) e, depois, para Vitória do Mearim, localizada na norte do Estado do Maranhão (a $183 \mathrm{Km}$ de São Luís), na microrregião da baixada maranhense. Certamente o rendimento salarial do pai de Agostinho permitiu o provimento da família e o investimento nos estudos para os filhos em cidades maiores, uns em São Luís e outros em Parnaíba, hoje o segundo município mais populoso do Estado do Piauí.

Os pais de Agostinho tiveram nove filhos, sendo sete homens e duas mulheres. As escolas onde estes estudaram no ensino básico revelam o peso das estratégias educativas para o sucesso social e econômico da família. Os três homens mais velhos estudaram no Liceu Maranhense, escola pública prestigiosa àquela época em São Luís, capital do estado. Os outros quatro homens, incluindo Agostinho, estudaram no Colégio Marista, escola privada e confessional católica, que historicamente formou parte das elites ludovicenses. As duas mulheres, quanto a elas, estudaram na escola Rosa Castro, ${ }^{8}$ uma antiga escola para mulheres que gozava de um prestígio equivalente ao Liceu Maranhense e ao Colégio Marista.

\footnotetext{
${ }^{8}$ A escola Rosa Castro tratava-se de uma Escola Normal feminina de São Luís que foi criada em 1916. A sede própria da escola localizava-se na avenida Gomes de Castro no Centro. Esta escola foi responsável, principalmente entre 1920 e 1940, pela formação de vários professores e professoras que lecionavam no Estado. A escola foi extinta na década de 1980 (MOTTA, s/d).
} 
Cursar o ensino básico em escolas tradicionais de São Luís certamente é um dos elementos que deve ser levado em conta, que contribuiu para a aquisição de um capital escolar e cultural determinantes para explicar o fato de que mais da metade dos filhos foram direcionados no ensino superior aos cursos de Direito e Medicina, dois cursos que são ainda os mais prestigiosos e os mais concorridos nas universidades. Dos filhos dois são advogados, o primeiro, especialista em Direito Agrário, reside e trabalha em Goiânia (Goiás), onde é escritor e, também, professor da Universidade Federal, além de já ter sido vice Reitor desta instituição. O segundo, além de advogar já foi presidente da OAB em São Luís e Secretário de Segurança Pública do Estado do Maranhão. Os outros três são da área de Medicina. Uma médica pediatra, sua irmã mais nova, que segundo Agostinho já ensinou no Technology. Um médico psiquiatra, que também foi professor no Technology. E o próprio Agostinho, que se formou primeiro em Medicina Veterinária, antes de orientar sua formação para a área da Educação, tornando-se pedagogo.

Dos outros filhos, um (já falecido) foi professor e administrador fundador do Technology em São Luís, apesar de ter morado grande parte da sua vida em Campinas, São Paulo. Há ainda um Cartógrafo que trabalhou na Editora Abril e agora tem sua própria editora. Este reside em São Roque, estado de São Paulo. Na época da entrevista realizada com Agostinho, este cartógrafo cursava o doutorado em Filosofia. Por fim, há uma administradora e um agrônomo, sobre os quais Agostinho não deu muita informação.

Agostinho tem dois filhos e estes fizeram seu Ensino Médio no Colégio Pitágoras ${ }^{9}$ de São Luís, uma escola privada de expressão na-

\footnotetext{
${ }^{9}$ Trata-se de uma escola privada que é parte de uma rede de ensino nacional e internacional que inicia suas atividades desde 1960 em Minas Gerais com o Curso pré-vestibular Pitágoras e que culmina em 1970 com a criação do Colégio
} 
cional e internacional que chega a São Luís em 1989, em parceria com a Alumar. ${ }^{10}$ Posteriormente o mesmo grupo funda a Faculdade Pitágoras que em 2011, compra a Faculdade Atenas Maranhense (FAMA). Contudo, os filhos de Agostinho se dirigiram ao ensino superior fora do Brasil. O mais velho estudou e se formou em Relações Internacionais na Inglaterra, e o outro é formado em Turismo, na Costa Rica. A esposa de Agostinho, Cecília Martins (nome fictício), é formada em Administração pela antiga Federação das Escolas Superiores do Maranhão - FESM, criada em 1972 e transformada em Universidade Estadual do Maranhão em 1981 e tendo seu funcionamento autorizado em 1987. ${ }^{11}$ Cecília Martins é maranhense, do município de Turiaçu, que fica a $460 \mathrm{~km}$ da capital numa rota pela MA 209 (e 230km pelo mar, via a embarcação Ferry Boat) e, segundo Agostinho, ela é "filha de Português, Português mesmo legítimo”. O entrevistado não revelou informações sobre a profissão e escolarização dos pais de sua esposa, mas a sua inserção como professora e depois administradora do $T e$ chnology e do Colégio Inovação são importantes para esse trabalho e serão trabalhadas no tópico seguinte.

No que diz respeito ao ponto de vista subjetivo do agente social entrevistado, destaca-se a história da escola, seu lugar no espaço urbano, a relação de Agostinho com o pai e com a educação, as formas

Pitágoras Cidade Jardim. Desde 1979 o Grupo Pitágoras faz parcerias com grandes empresas como Mendes Júnior, Norberto Odebrecht, Andrade Gutierrez. Atualmente tem parcerias com Vale, Alumar, Embraer, Mineração Taboca e outras. Ressalta-se que as compras, fusões e parcerias com instituições educacionais que o Grupo Pitágoras vem realizando a partir dos anos 2000. Cf. essas informações em www.colegiospitagoras.com.br.

${ }^{10}$ Alumar é um consórcio gerenciado pela ALCOA-Brasil, situada a 18 km de São Luís, que iniciou suas atividades em 1984, e é formada atualmente pelas empresas com tradição nas áreas de produção de alumina e alumínio (Alcoa, South32 e Rio Tinto).

${ }^{11}$ Para mais informações sobre isso consultar www.uema.br. 
de distinção social da escola e sua relação com o ENEM.

Uma pequena observação a ser feita nas informações dadas pelo nosso interlocutor e seus escritos é a ocultação das datas, de nascimento, deslocamento da cidade de Buriti, fundação do seu instituto Tecnology etc. O que torna os fatos ahistóricos, e que corresponde bem à ideia do "mito fundador" sobre o qual enfatizaremos a seguir.

\section{Do Technology ao Colégio Inovação: continuidades e "mitos de origem" como formas de legitimação social}

No primeiro momento da entrevista buscou-se saber sobre a história de fundação da escola. Imediatamente Agostinho perguntou: “qual delas o Technology ou o Colégio Inovação?”. De acordo com Agostinho “o Technology é o pai e a mãe do Colégio Inovação”. Para este agente social a história das duas instituições está intrinsecamente ligada, e faz parte da história do seu grupo familiar. Segundo ele, o Technology foi fundado em 1969, em parceria com seu irmão e o Colégio Inovação, foi fundado no ano de 2001.

O Technology é uma escola de idiomas fundada em São Paulo em 1950. Sobre a fundação do polo ludovicense, Agostinho explica:

Quando eles chegaram em São Luís eles nos procuraram; mais especificamente o meu irmão, que tinha um curso de Inglês; quando nós fomos ser treinados, naquela época, eu era um jovem adolescente... quando o Technology chegou em São Luís eu tinha quatorze anos, fui ser aluno do Technology e o meu irmão já era professor de Inglês (ENTREVISTA COM AGOSTINHO MARTINS, 2016).

O primeiro aspecto a ser destacado está ligado às estratégias educativas da família. O irmão mais velho de Agostinho foi professor de 
Inglês. Agostinho não informa se ele fez algum curso de Inglês ou se ele era formado em Letras, com ênfase no Inglês como língua estrangeira. Sobre a formação, Agostinho apenas afirma que era professor e administrador. Certamente seria preciso investigar o que significava ter o domínio de uma língua estrangeira em São Luís no fim da década de 1960, mas é possível afirmar como hipótese, de que se tratou de um critério de distinção social. Falar uma língua estrangeira, mais especificamente o Inglês àquela época, funcionava e funciona hoje, como um capital linguístico no mercado dos bens simbólicos. Como dizia Bourdieu, o habitus linguístico se distingue de uma competência (Chomsky), pelo fato de não ser simples produção de discurso, mas produção de discursos ajustada a uma "situação", ou antes, ajustada a um mercado ou a um campo social (BOURDIEU, 2019, p. 116-117). Outro aspecto a ser considerado, é que o irmão de Agostinho, além de sua inserção como professor no campo educacional, também inicia a inserção da família como fornecedora de serviços educacionais. Isso é decisivo para que Agostinho se envolva com o ensino, inicialmente como professor de Inglês, e, posteriormente, como pedagogo e diretor de escola.

No relato da história do Technology aparecem alguns elementos que podem ser interpretados como uma forma de distinção social dessa instituição, algo que a diferencia das demais; ao menos é assim que o porta-voz da escola busca o controle das impressões sobre a instituição, algo que posteriormente aparece em relação ao Colégio Inovação. O primeiro elemento que aparece duas vezes, qual seja: a afirmação de que "a ideia sempre foi educar através do ensino de idioma” ou quando ele diz que "o Inglês ou qualquer que seja o idioma não pode ser um fim em si mesmo, ele é um instrumento para que as pessoas se eduquem”. Esse aspecto é apresentado não só como uma 
forma de distinção, mas também como uma forma de elo histórico com o ensino e com uma forma de enxergar o papel da educação que legitimaria a fundação do Colégio Inovação. Aliás, é outro elemento de distinção social do Technology que, de acordo com a narrativa do entrevistado, faz com que os próprios pais dos alunos solicitem que seja aberta uma escola de ensino básico. Vê-se nesse sentido a desigualdade de acesso a esse tipo de capital linguístico, uma vez que a aprendizagem de uma língua estrangeira não se faz de maneira natural, e a entrada num curso de Inglês, nesse caso, na época e atualmente, demanda recursos econômicos, pois são geralmente caros, exigindo a posse de capital econômico e cultural. Outrossim, isso exige que se conheça “as condições de aceitabilidade” desse capital linguístico no mercado educacional e simbólico. Como bem lembrou Bourdieu (2019, p. 95): “aprender uma linguagem é aprender ao mesmo tempo que essa linguagem será rentável nessa ou naquela situação”.

Essa espécie de "mito de origem” da fundação da escola funciona como uma forma de legitimação da sua fundação, tendo em vista que o porta-voz apresenta a escola como sendo fruto do reconhecimento de um trabalho anterior, e como sendo demandada pelos próprios pais. Dizer isso, na narrativa de nosso interlocutor, é afirmar que, apesar de ser uma escola privada, uma empresa, ela não surge por interesses econômicos, mas sim por conta de uma “vocação” diferenciada no ramo de ensino ou, como complementaremos mais à frente, por conta de uma pedagogia que vai além do ensino escolar.

No que concerne à localização socioespacial do instituto de idiomas no espaço urbano em São Luís, encontramos a seguinte afirmação:

O Technology nasceu na rua de São João (Centro, rua 13 de maio), depois foi para a rua do Machado, na Av. Beira-mar, depois foi para 
a Praça Gonçalves Dias, em seguida para o Bairro São Francisco e Renascença. E foi lá, no Renascença, que aconteceu esse convite, essa cutucada dos pais para abrimos o Technology uma escola de educação básica. Aí começamos a construir o prédio da Avenida dos Holandeses ${ }^{12}$ (ENTREVISTA COM AGOSTINHO MARTINS, 2016).

Sobre sua trajetória no espaço social-urbano de São Luís, este agente social afirma que já morou no Parque Amazonas, Felipinho, Cohama, São Francisco, Renascença e atualmente mora na Ponta d'Areia. ${ }^{13}$ Essa mobilidade no espaço urbano da cidade acompanha uma ascensão social visto que a sequência mostra que o poder aquisitivo das famílias habitantes desses bairros cresce consequentemente.

Outro aspecto que serve como justificação do investimento de Agostinho na educação é explicado a partir da história familiar, mais especificamente, da relação do pai com a educação. Como vimos acima, o pai de Agostinho trabalhava na zona rural, como lavrador, "não estudou em escolas, chegou apenas ao terceiro ano primário, na época, mas estudando em casa, com professor particular”. Segundo Agostinho

...um dia, roçando com sua enxada, num sol a pino, revoltado com aquele sofrimento todo, já com alguns filhos, sofrendo as mazelas do sol do sertão, ele teve uma espécie de revolta com aquela vida e disse, prometeu, jurou, que os filhos não teriam esta vida. E a partir daquele instante ele saiu da roça e foi para um interior mais próximo

\footnotetext{
${ }^{12}$ Em termos topográficos na cidade de São Luís, na sequência apresentada, do Centro Histórico ao Renascença, Holandeses/Calhau, a cidade ao longo dos anos conheceu um processo de urbanização e de enriquecimento, com a instalação de condomínios, shopping e centros comerciais e empresariais, abrigando os serviços (escritórios, consultórios, bancos, estabelecimentos escolares e comerciais) voltados para a classe mais rica da população.

${ }^{13}$ A ponta d'Areia, que nomeia uma das praias de São Luís, abriga também uma região de condomínio de alto padrão e poder aquisitivo. Por onde também passa a Av. dos Holandeses.
} 
(ENTREVISTA COM AGOSTINHO MARTINS, 2016).

Essa forma de apresentar o pai indica uma tentativa de construir uma espécie de explicação que positiva a origem social ao positivar o esforço pessoal para superar sua própria condição socioeconômica. Uma explicação que recusaremos aqui, apesar de considerá-la como uma forma de justificação dos agentes para explicar seu sucesso social.

Agostinho revela ainda, como era decisivo migrar do interior do Maranhão para a capital, para terminar o ensino básico:

....a história do meu pai é pautada dessa luta, ele disse: 'meus filhos não terão essa vida sofrida que eu tenho, eu juro que pelo menos o mais velho terminará o Ginásio’. Porque naquela época, quem terminava o Ginásio era doutor. Porque nos interiores não havia Ginásio, Ginásio é hoje do quinto ao nono ano. Não havia Ginásio no interior. Então, quando os filhos chegavam no Ginásio eles iam para cidade (ENTREVISTA COM AGOSTINHO MARTINS, 2016).

Por fim, Agostinho enfatiza a relação do pai com a educação, apesar deste ter estudado pouco:

Então, por que que a história do meu pai é interessante para sua pergunta? Porque ele pensou assim: 'meus filhos não terão a vida que eu tenho e o caminho é a educação. Porque eu não tenho dinheiro, eu não tenho terras, eu não tenho gado, eu não tenho nenhum bem material. E eu não tenho por que não tenho educação. Então meus filhos vão estudar, eles não vão ser como eu sou'. E por isso que todos nós lutamos muito. Se você perguntar qual a razão do sucesso da família, é que todo mundo que se colocou e ainda se coloca nos estudos, foi com essa garra que o pai passou para gente. É uma garra que não era só motivação, era uma garra de obrigação. A gente podia falhar em tudo para o meu pai, menos na escola. Então para o nosso pai era sagrado. E isso realmente não só nós herdamos do pai como passamos para nossos filhos. A família inteira tem uma 
queda, uma motivação para educação (ENTREVISTA COM AGOSTINHO MARTINS, 2016).

Todo o relato de Agostinho sobre a história da família e mais especificamente sobre a relação do seu pai com a educação nos oferece alguns aspectos relevantes para a pesquisa, porém oculta outros. Os relatos de Agostinho revelam efetivamente o peso das estratégias educativas para as estratégias de reprodução social do grupo familiar. Do ponto de vista objetivo a migração para São Luís e o investimento em "boas escolas” públicas ou privadas (Liceu e Colégio Marista, como vimos anteriormente) no Ensino Médio, são suficientes para confirmar este aspecto.

Por outro lado, Agostinho não revela o papel da mãe na história da família e desse empreendimento, que é uma coadjuvante não citada, o que pode indicar tanto o papel subordinado da mulher do interior da sociedade maranhense numa dada época no que tange às decisões familiares, quanto uma espécie de forma "patriarcal” de contar uma história, tendo em vista o papel muito comum da mulher (ao menos nas classes mais baixas) na educação dos filhos em oposição ao papel do homem de sustento da família.

Além disso, outra espécie de “mito de origem” aparece no seu relato: um tipo de relação original com a educação que advém da família, especificamente do pai, e que legitima a “vocação” de Agostinho e da família para a educação. Efetivamente, a "herança” que Agostinho se refere pode ser interpretada sociologicamente como uma disposição adquirida que direciona a aspiração do êxito social, da ascensão social, via educação. A escola passa ser acreditada como via de ascensão social, uma vez que sua família não predispunha de capital cultural, no sentido entendido por Bourdieu. Nesse aspecto alguns sociólogos mais recentes adotaram perspectivas mais microssocioló- 
gicas, qualitativas e etnográficas a fim de compreender as estratégias de agentes sociais frente à escola. Essas pesquisas se interessam aos “sucessos paradoxais" de crianças oriundas de universos sociais que não predispõem de excelência escolar (LAHIRE, 1995), e pelas estratégias escolares implementadas pelas famílias pela experiência escolar (DUBET; MARTUCELLI, 1996), analisando o “efeito-classe”, o “efeitos-mestres”, “efeitos-estabelecimento”, sobre o sucesso escolar (JOURDAIN; NAULIN, 2017; DURU-BELLAT; VAN ZANTEN, 2006).

Outra questão colocada para Agostinho foi sobre a participação da sua esposa na história de fundação do Technology e do Colégio Inovação. Sobre isso ele respondeu o seguinte: “a minha esposa fez intercâmbio nos Estados Unidos quando ela era adolescente, e quando voltou, ela foi ensinar Inglês no Technology. Começamos a lecionar Inglês no mesmo ano”. Cecília Martins ${ }^{14}$ é formada em Administração, pela UEMA (Universidade Estadual do Maranhão) e "hoje é a diretora administrativa das duas empresas”. Essa concepção da escola como empresa dada pelo próprio entrevistado confirma nossa hipótese exposta desde o início. A escola não é só concebida como empresa, mas deve ser administrada como tal.

Quando perguntado se o Colégio Inovação é um projeto do casal, ele respondeu:

Sim! Na verdade, nós começamos a ensinar no Technology. Quando meu irmão foi embora para São Paulo, eu assumi, não éramos casados ainda, mas eu assumi a direção da escola. Aí, logo depois de um ano que estávamos no Technology, nós resolvemos comprar o Technology do meu irmão... Aí ela se formou em administração, largou a sala de aula, o magistério, foi cuidar da parte administrativa. E eu tinha saído da veterinária, estava na pedagogia, fiquei sempre na

\footnotetext{
${ }^{14}$ Trata-se de um nome fictício.
} 
área pedagógica e ela sempre na área administrativa (ENTREVISTA COM AGOSTINHO MARTINS, 2016).

Nesse caso, o papel de Cecília Martins parece ter sido fundamental; isso associado a diversos fatores: sua competência administrativa (ao mesmo tempo formal, garantida pelo diploma, e prática, no sentido de aquisição de uma "habilidade”); a formação pedagógica de Agostinho, e seus capitais econômicos. Essas prerrogativas aumentam as chances de obter êxito num empreendimento educacional privado que efetivamente exige condições que não são necessariamente acumuladas por um único agente social.

\section{Três aspectos de distinção no espaço escolar: pedagogia, tecnologia e filosofia}

Outra questão importante colocada, foi sobre a pedagogia escolar. Agostinho já havia explicado que o Colégio Inovação ${ }^{15}$ é um sistema de ensino nacional que funcionava num sistema de parceria que poderia se instalar em qualquer escola e usando o seu material didático. Depois o Colégio Inovação passou a funcionar como franquia, ou seja, quando é aberta uma unidade utilizando “não só o material didático”, mas também a "identidade visual, a propaganda, o comercial, as cores, o fardamento”. No que tange à pedagogia, Agostinho destaca que a adotou no Colégio Inovação pela sua ênfase no vestibular, por sua utilização da tecnologia e pela sua perspectiva transdisciplinar de ensino.

\footnotetext{
${ }^{15}$ Vale ressaltar que Agostinho afirmou que o Inovação foi comprado pela Pearson, uma empresa de educacional de caráter mundial que, em São Luís, afirma Agostinho, comprou também o Technology, a Microlins (empresa que oferece principalmente cursos na área de informática), a Wizard (empresa que oferece cursos de idiomas) e "mais ou menos umas oito a dez entidades educacionais" que a Pearson teria comprado.
} 
Eu me encantei com o Inovação por três motivos, que na época eram mais fortes ainda. Primeiro, a questão mesmo do vestibular. O Inovação nasceu de cursinho. Então, invés de começar pela educação infantil, eles começaram lá de cima. Então eles ficaram muito fortes no vestibular; o Inovação foi campeão de vestibulares, ainda é em muitos estados do Brasil. (...) A segunda coisa que me apaixonou no Inovação foi a tecnologia. Eu sou vidrado em tecnologia em educação. E o Inovação foi, e ainda é, a escola que tem mais recursos tecnológicos do Brasil. O Inovação desenvolveu um projeto com a USP chamado sala do futuro; hoje que a gente vê em sala de aula projeção em 3D, de navegação na internet, uma série de coisas, o Inovação foi precursor disso no Brasil quando ainda nem tinha essa navegação toda na internet. O Inovação foi o primeiro a usar sistema 3D na sala de aula, foi o primeiro a usar os e-books, os livros eletrônicos, foi o primeiro a usar no Brasil e eu me encantei com isso. E a terceira coisa que eu gostei do Inovação, foi na educação fundamental, que a gente só veio aderir depois, mas eu me apaixonei na educação fundamental porque o Inovação já naquela época tinha a ideia de acabar com o currículo linear de disciplinas e mudou para eixos temáticos. (...) É mais do que uma inter é uma transdisciplinaridade, ou seja, em vez de procurar estudar um conteúdo de uma matéria, eles estudam um problema... (ENTREVISTA COM AGOSTINHO MARTINS, 2016).

Essas três características do Colégio Inovação são também formas de distinção social. A primeira, que diz respeito ao vestibular, revela uma relação ambígua com este, sobretudo com o ENEM, tendo em vista que por um lado Agostinho afirma que "embora não seja favorável à educação voltada com essa”neura” de vestibular“, por outro”a escola tem essa finalidade, de preparar as pessoas para a universidade”. Tratando especificamente do ENEM ele afirma:

...eu acho que ele tá mudando de cima para baixo, na verdade a coisa devia começar da educação infantil chegando lá na universidade. Mas de qualquer forma, o ENEM, mudando o tipo de perguntas, de questões de vestibular para acesso à universidade, ele termina forçando uma mudança no ensino médio que por sua vez vai for- 
çar uma mudança no ensino fundamental e infantil. E isso é muito bom. Ou seja, ele coloca um problema na prova, ele não coloca mais uma pergunta de conteúdo. Isso foi um lado muito legal do ENEM, muito bacana, realmente é um ponto de mutação no exame. Todavia o ENEM acirrou uma supervalorização do exame para a universidade, porque essa pontuação de escolas, já que o exame é nacional, quando não era nacional não era tanto assim, há uma correria muito grande, aumentou um pouco mais a idolatria do exame para a universidade. As próprias escolas estão concorrendo e com elas os alunos concorrem de uma forma mais febril, endeusando de uma forma exagerada a escola e o aluno que passam o ENEM com a pontuação alta (ENTREVISTA COM AGOSTINHO MARTINS, 2016).

Essa primeira característica revela as tensões presentes numa escola privada de alto custo adaptada ao modelo da escola neoliberal de alta concorrência que precisa não somente aprovar no vestibular, mas também apresentar algo que a diferencie das demais no que diz respeito ao ensino, não podendo "reduzir" o seu papel social, o que seria reduzir sua importância social, apenas à aprovação no vestibular e muito menos negar essa dimensão da aprovação.

A segunda característica é a utilização da tecnologia, que opera como uma forma de dupla distinção social, tanto por se utilizar da tecnologia quanto por um certo pioneirismo reivindicado nesse uso. Além disso, a utilização da tecnologia é o que justifica, segundo o ponto de vista deste agente social, tanto um alto preço das mensalidades do Colégio Inovação quanto a localização no bairro do Calhau. Ao ser indagado o porquê desse bairro Agostinho responde o seguinte:

O Inovação é uma escola cara. Sempre foi uma escola muito cara, o Technology também. Por que que é cara? Porque o Inovação teve essa vertente da tecnologia. Hoje é até mais barato se usar tecnologia, mas no início do Inovação, para você ter uma ideia, a nossa sala 3D, nós fomos a terceira escola Inovação do Brasil a usar uma 
sala 3D, e na época a sala 3D do Inovação eu me lembro que ela custou o preço de um carro, foi financiado durante muitos anos por um valor imenso. Então, esse custo da tecnologia força com que tenhamos alunos que possam pagar (ENTREVISTA COM AGOSTINHO MARTINS, 2016).

Em complementação a isso Agostinho afirma que

No entanto, o Inovação, sabendo da necessidade de não só atender a classe de elite econômica, o Inovação tem projetos sociais. E hoje nos mantemos um projeto social num bairro chamado Residencial Pirâmide, onde nos mantemos uma escolinha comunitária, que tem cerca de 100 alunos. Nós não só mantemos essa escola, como nós também fazemos um trabalho de interação, de troca de compartilhamento, entre o que nós ensinamos aqui e o que os alunos de lá aprendem e os professores e lá também. Então a gente trabalha o lado da responsabilidade social também. É uma pena que, como a escola Inovação tenha esses custos, o Inovação não possa se espalhar em lugares onde pessoas poderiam ter acesso a sua tecnologia (ENTREVISTA COM AGOSTINHO MARTINS, 2016).

Cabe aqui um parêntese sobre a noção de "responsabilidade social". Designar-se como tendo "responsabilidade social”, palavra muito comum em grandes empresas, funciona como uma denegação e ao mesmo tempo revelação - de que apesar de todas as justificativas pedagógicas ou "filosóficas" sobre suas ações, trata-se de uma escola que, principalmente (mas não exclusivamente) por suas altas mensalidades atende a grupos privilegiados economicamente. Além disso, a "responsabilidade social” é uma maneira de negociar uma "boa imagem” no mundo social, ou seja, a possibilidade de apresentar-se como uma instituição que transcende o papel escolar da escola.

Por fim, a terceira característica, que ele apresenta como uma forma de ensino transdisciplinar, está ligada a uma perspectiva pedagógica específica, a uma concepção sobre o que significa educar. Esse é um critério de diferenciação, de distinção social, tendo em 
vista que a escola transcende o seu papel de oferecer os conhecimentos do ensino básico e de preparar para o vestibular. A perspectiva de Agostinho, que já estava presente na forma que o Technology tinha de se diferenciar, sendo, segundo seu relato a causa do pedido dos pais para a criação de uma escola de ensino básico, é que

...o conteúdo é instrumento, a tecnologia é instrumento, o Enem é instrumento, a universidade é instrumento, o diploma, tudo é instrumento. Que na verdade a grande questão que o aluno desde cedo deve se preocupar é com, é um pouco o que a Logosofia ${ }^{16}$ defende, a questão do sentido da vida (ENTREVISTA COM AGOSTINHO MARTINS, 2016).

Quando questionado sobre o que o Colégio Inovação apresenta de diferente das demais escolas, Agostinho deu ênfase justamente a esse aspecto que ele chamou de uma "filosofia de trabalho":

...mas a gente tenta fazer uma escola que ensina com a vida. Nós nunca gostamos desse slogan ensinar para vida, nunca gostamos. Porque ensinar para vida dá a ideia de que você aprende, aprende, aprende, e pronto, agora está pronto para viver. E isso não faz sentido para nós. Isso é incongruente. Nós sempre quisemos ensinar com a vida. (...) Não queremos que eles esperem se formarem, para pronto, agora estou pronto para viver. Isso é incongruente para nós. Por isso é que nós achamos que esse é um diferencial (ENTREVISTA COM AGOSTINHO MARTINS, 2016).

É relevante que apesar de todas as ambiguidades da ação escolar do Colégio Inovação, percebidas, sobretudo, na relação da escola com o vestibular e com a tecnologia, o agente social entrevistado insista em enfatizar uma questão "filosófica” - "o sentido da vida” - como elemento fundamental que o diferencia das demais escolas. Se essa

\footnotetext{
${ }^{16}$ Doutrina ético-filosófica, desenvolvida pelo pensador argentino González Pecotche (1901-1963), que busca ensinar o homem a conquistar sua autotransformação através da evolução consciente do pensamento.
} 
é a particularidade do Inovação, é preciso refletir sobre as condições sociais que a tornam possível.

Concluímos essa seção afirmando que as características distintivas do Colégio aqui analisado, espelham o que Christian Laval (2019) afirma:

A introdução de mecanismos de mercado no funcionamento da escola por intermédio da promoção da "escolha da família", isto é, de uma concepção consumidora da autonomia individual, leva à desintegração da instituição escolar. O autor completa afirmando que o novo modelo de escola funciona a partir da "diversidade", da "diferenciação”, em função de seu público e das “demandas” (LAVAL, 2019, p. 23).

Esses discursos e práticas concernentes à gestão educacional revestem de eufemismo o poder que se oculta em slogans tais como: "gestão participativa”, “comando é mobilização”, “autoridade é suporte, supervisão e ajuda”; "impor é convencer”, “dirigir não é mais comandar”, mas “motivar”, “exercer liderança”, “animar é, sobretudo educar” (LAVAL, 2029, p. 257).

\section{Considerações finais}

O presente trabalho buscou apreender as propriedades sociais e a trajetória escolar de um grupo familiar que estabeleceu ao longo de cinquenta anos um verdadeiro empreendimento educacional na cidade de São Luís do Maranhão, constituindo-se como referência do ensino, contudo, voltado para grupos sociais cujo primeiro crivo é seu alto capital econômico, ${ }^{17}$ visto que as mensalidades demandam alto poder

\footnotetext{
${ }^{17}$ Costa (2017) mostra que os dados oficiais do INEP (Instituto Nacional de Estudos e Pesquisas Educacionais Anísio Teixeira), em 2014, classificavam esta escola como tendo um INSE (Indicador de Nível Socioeconômico) "muito alto”, o que
} 
aquisitivo. Inicialmente tratou-se de um instituto de formação em idioma estrangeiro, com ênfase e destaque para o curso de Inglês; e em seguida, a instalação de uma franquia que faz parte de uma rede de ensino nacional e internacional, chamado aqui de Colégio Inovação. O objetivo principal da nossa análise foi objetivar as estratégias de reprodução social e cultural do grupo familiar que administra uma das “escolas de elite” em São Luís. Tal objetivo se insere em preocupações de pesquisa mais amplas, relacionadas a um projeto de pesquisa e a uma tese de doutorado em andamento, onde visamos elaborar e analisar uma cartografia da distribuição espacial e social dos estabelecimentos de ensino em São Luís e objetivar as estratégias de reprodução das famílias ligadas as demais "escolas de elite” ludovicense por meio das estratégias de escolhas dos estabelecimentos de ensino. ${ }^{18}$

As escolas e suas orientações formativas e pedagógicas são criadas em função da demanda no mercado educacional que nos últimos anos tem se estabelecido arranjado com a economia neoliberal. Esse aspecto se sobressai nos discursos de um dos nossos interlocutores, em relatos que reconstituem a história social do grupo familiar, mas também da história da fundação das instituições supracitadas. Como vimos, a instalação do curso de Inglês em São Luís se insere no contexto dos empreendimentos da nova economia minero-metalúrgica advinda na capital maranhense nos anos 1970. Segundo nosso entrevistado, a captação do empreendimento escolar do Colégio Inovação, é

implica que a maioria dos alunos da escola afirmou ter renda entre 5 e 7 salários (45\%) mínimos e parte considerável acima de 7 salários (28\%). Só dez escolas de São Luís apresentavam essa classificação, todas privadas.

${ }^{18} \mathrm{O}$ projeto citado, intitulado "Segregação espacial e escolar: sociologia da distribuição geográfica dos estabelecimentos de ensino em São Luís” se desenvolveu entre 2014 a 2017. A dissertação já citada anteriormente (COSTA, 2017) foi um dos desdobramentos deste projeto. A pesquisa iniciada na dissertação agora está sendo desenvolvida na tese de doutorado intitulada "As famílias e as 'escolas de elite’ de São Luís: escolhas e estratégias de reprodução social”. 
um apelo de algumas famílias que desejavam uma escola que visasse à preparação para as novas demandas da sociedade moderna e tecnológica. Esses novos empreendimentos educacionais, e as reformas no sistema escolar se ajustam cada vez mais às novas configurações da economia neoliberal que busca cada vez mais fazer da escola uma empresa (LAVAL, 2019).

Apesar dos agentes do Colégio Inovação, uma dentre as "escolas de elite” ludovicenses, dizerem apoiar-se no “diletantismo” próprio aos grupos dominantes, estabelecendo objetivos não utilitários ou instrumentais tais como "formar para vida” ou "aprendizagem significativa”, seu sistema de ensino está voltado para a concorrência e a competitividade ora na inserção no espaço acadêmico universitário ora dos futuros empreendimentos econômicos próprios da economia neoliberal. A escola se apoia ao mesmo tempo em valores da cultura ocidental, amplamente reconhecidos e institucionalizados em campos do saber legítimos (a filosofia) para orientar suas ações escolares, constituindo, inclusive, tipos particulares de ação escolar a partir destes. Por outro lado, essa escola estabelece, também, uma relação mais utilitária com a cultura dominante, apoiando-se no que é possível classificar, tomando o ENEM como base, de cultura escolar dominante.

A sociologia de um grupo familiar como tentamos fazer aqui, apoiada em material empírico biográfico (por entrevista e outros documentos autobiográficos), sem a intensão de fazer uma sociologia à escala do indivíduo, busca romper com a naturalização dos fenômenos sociais, em matéria de ascensão social, resultado do acaso ou das graças divinas. Se indivíduos, segundo seus recursos econômicos e culturais, podem negociar margens de manobras e arranjos das condições objetivas de mudanças nos percursos, essas condições nunca são desvin- 
culadas das interdependências e das condições sociais que funcionam ao mesmo tempo como "força restauradora" (DUBAR; NICOURD, 2017; MAUGER, 2015).

\section{Referências}

ALMEIDA, A. M. F. As escolas dos dirigentes paulistas. Belo Horizonte: Arvmentum, 2009.

ALMEIDA, A. M. F. A noção de capital cultural é útil para se pensar o Brasil? In PAIXÃO, L. P. e ZAGO, NADIR (orgs.). Sociologia da educação: pesquisa e realidade brasileira. 2 ed. Petrópolis, RJ: Vozes, 2011.

BOURDIEU, P. Os três estados do capital cultural. In BOURDIEU, P. Escritos de Educação. Petrópolis: Vozes, 2017, p. 79-88.

BOURDIEU, P.; PASSERON, J. C. Os herdeiros: os estudantes e a cultura. Florianópolis: Ed. da USFC, 2014.

BOURDIEU, P. "L'illusion biographique”, Actes de la Recherches en Sciences Sociales, v. 62, n. 1, p. 66-73.

BOURDIEU, P. Questões de Sociologia. Petrópolis: Vozes, 2019.

BRANDÃO, Z.; MANDELERT, D.; PAULA, L. de. A circularidade virtuosa: investigação sobre duas escolas no Rio de Janeiro. Cadernos de Pesquisa, v. 35, n. 126, p. 747-758, set./dez. 2005.

CENSO ESCOLAR. www.qedu.org.br. Acesso em 07/01/2017.

COSTA, L. A. dos R. As “escolas de elite” de São Luís: escolhas, segregação e estratégias de distinção escolar/Dissertação de Mestrado em Ciências Sociais-PPGCSoc-UFMA. Leandro Augusto dos Remédios Costa, 2017. 141 p.

DUBAR, C.; NICOURD, S. Les biographies en sociologie. Paris: La Découverte, 2017.

DUBET, F.; MARTUCELLI, D. À l'école: sociologie de l'expérience scolaire. Paris : Seuil, 1996.

DURU-BELLAT, M. ; VAN ZANTEN, A. Sociologie de l'école. Paris : Seuil, 2006. 
FRANÇOIS, J.-C.; POUPEAU, F. Le sens du placement scolaire: la dimension spatiale des inégalités sociales. Revue Française de Pédagogie, n. 169, 2009/4, p. 77-97.

GOFFMAN, E. A representação do eu na vida cotidiana. Petrópolis: Vozes, 2014.

HÉRAN, F. (1996). École publique, école privée: qui peut choisir? Économie et Statistique, n. 293, 3, p. 5-39.

JOURDAIN, A.; NAULIN, S. A teoria de Pierre Bourdieu e seus usos sociológicos. Petrópolis: Vozes, 2017.

LAHIRE, B. Tabeaux de familles: Heurs et Malheurs scolaires en milieux populares. Paris: Galimmard, 1995.

LAVAL. C. A escola não é uma empresa: o neoliberalismo em ataque ao ensino público. São Paulo: Boitempo, 2019.

LE GOFF, J.-P. La barbarie douce, la modernisation aveugle des entreprises et de l'école. Paris: La Découverte, 1999.

MAUGER, G. Âge et générations. Paris: La découverte, 2015.

NOGUEIRA, M. A. Classes médias e escola: novas perspectivas de análise. Currículo sem Fronteiras, v. 10, n. 1, p. 213-231, Jan/Jun 2010.

PEROSA, G. Educação diferenciada e trajetórias profissionais femininas. Tempo Social, revista de sociologia da USP, v. 20, n. 1. 2008.

SCHWARTZ, O. Le baroque des biographies, Cahiers de philosophie, n. 10, p. 173-183.

WEBER, M. A objetividade do conhecimento nas Ciências Sociais. In: WEBER, M. Ensaios sobre a teoria das Ciências Sociais. São Paulo: Centauro, 2003.

WEBER, M. Economia e Sociedade: fundamentos da sociologia compreensiva. 4. ed., Brasília: Editora Universidade de Brasília, 2012. 


\title{
Resumo:
}

O presente trabalho propõe uma análise da trajetória social e das estratégias de reprodução social de um grupo familiar fundador de uma "escola de elite” de São Luis. O caso apresentado é um exemplo de como processos de socialização e escolarização de determinados agentes sociais que compõem uma família dirigente de uma escola, são decisivos para o tipo de estratégia de distinção desta num espaço escolar e urbano estratificado, em que o modo como a escola se apresenta e os valores que defende implicam, em atrair ou não, determinadas famílias para o seu empreendimento. Os dados empíricos foram construídos através de entrevista e leitura de documentos escritos pelo próprio agente entrevistado, um dos proprietários da instituição escolar analisada. O discurso dos dirigentes da escola revela uma relação com os discursos da "escola neoliberal” que tem emergido no Brasil e no mundo, desde a década de 1970.

Palavras-chave: Reprodução social; trajetórias; escola de elite.

\begin{abstract}
:
This paper proposes an analysis of the social trajectory and strategies of social reproduction of a family group that founded a "elite school" in São Luis. The case presented is an example of how the socialization and schooling processes of certain social agents that make up a school's governing family are decisive for the type of strategy to distinguish the latter in a stratified school and urban space, in which the way the school it presents itself and the values it defends imply, in attracting or not, certain families for its enterprise. The empirical data were constructed through interviews and reading of documents written by the interviewed agent, one of the owners of the analyzed school institution. The speech of school leaders reveals a relationship with the speeches of the "neoliberal school" that has emerged in Brazil and in the world, since the 1970s.
\end{abstract}

Keywords: Social reproduction; trajectories; elite school. 
130 Sociologia de um grupo familiar administrador de uma escola de elite

Recebido para publicação em 16/04/2020.

Aceito em 06/10/2020.

Revista de Ciências Sociais - Fortaleza, v. 51, n. 3, nov. 2020/fev. 2021, p. 101-130. 